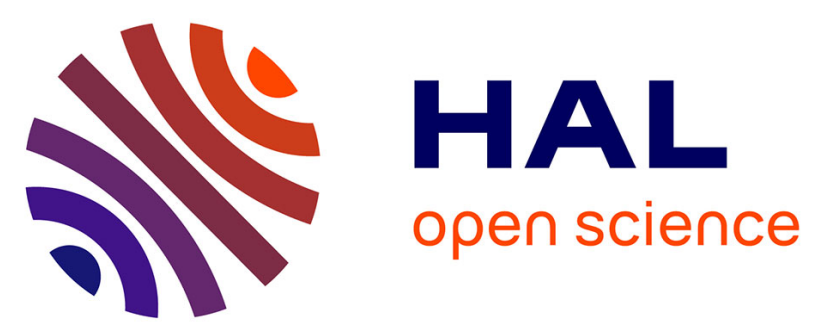

\title{
Joint effects of patch edges and habitat degradation on faunal predation risk in a widespread marine foundation species
}

Kevin Hovel, J. Emmett Duffy, John Stachowicz, Pamela Reynolds, Christoffer Boström, Katharyn Boyer, Stéphanie Cimon, Mathieu Cusson, Fredrick Joel Fodrie, Karine Gagnon, et al.

\section{To cite this version:}

Kevin Hovel, J. Emmett Duffy, John Stachowicz, Pamela Reynolds, Christoffer Boström, et al.. Joint effects of patch edges and habitat degradation on faunal predation risk in a widespread marine foundation species. Ecology, 2021, 102 (5), pp.e03316. 10.1002/ecy.3316 . hal-03428440

\author{
HAL Id: hal-03428440 \\ https://hal.science/hal-03428440
}

Submitted on 16 Nov 2021

HAL is a multi-disciplinary open access archive for the deposit and dissemination of scientific research documents, whether they are published or not. The documents may come from teaching and research institutions in France or abroad, or from public or private research centers.
L'archive ouverte pluridisciplinaire HAL, est destinée au dépôt et à la diffusion de documents scientifiques de niveau recherche, publiés ou non, émanant des établissements d'enseignement et de recherche français ou étrangers, des laboratoires publics ou privés. 
DR. KEVIN A. HOVEL (Orcid ID : 0000-0002-1643-1847)

DR. MATHIEU CUSSON (Orcid ID : 0000-0002-2111-4803)

DR. KARINE GAGNON (Orcid ID : 0000-0002-0971-7740)

DR. JENNIFER L. RUESINK (Orcid ID : 0000-0001-5691-2234)

MS. SHELBY L. ZIEGLER (Orcid ID : 0000-0001-7218-0811)

Article type : Articles

Journal: Ecology

Manuscript type: Article

Running head: seagrass habitat edges and predation

Joint effects of patch edges and habitat degradation on faunal predation risk in a widespread marine foundation species

Kevin A. Hovel ${ }^{1 *}$, J. Emmett Duffy ${ }^{2}$, John J. Stachowicz ${ }^{3}$, Pamela Reynolds ${ }^{2,3}$, Christoffer Boström ${ }^{4}$, Katherine Boyer ${ }^{5}$, Stéphanie Cimon ${ }^{6}$, Mathieu Cusson ${ }^{6}$, F. Joel Fodrie ${ }^{7}$, Karine Gagnon ${ }^{8}$, Clara M. Hereu $^{9}$, Masakazu Hori ${ }^{10}$, Pablo Jorgensen ${ }^{11}$, Claudia Kruschel ${ }^{12}$, Kun-Seop Lee ${ }^{13}$, Masahiro Nakaoka $^{14}$, Nessa E. O’Connor ${ }^{15}$, Francesca Rossi ${ }^{16}$, Jennifer Ruesink ${ }^{17}$, Fiona Tomas ${ }^{18,19}$, Shelby Ziegler $^{7}$

${ }^{1}$ Department of Biology, San Diego State University, 5500 Campanile Drive, San Diego, CA 92182, USA

This article has been accepted for publication and undergone full peer review but has not been through the copyediting, typesetting, pagination and proofreading process, which may lead to differences between this version and the Version of Record. Please cite this article as doi: $\underline{10.1002 / \text { ecy.3316 }}$

This article is protected by copyright. All rights reserved 
${ }^{2}$ Tennenbaum Marine Observatories Network, Smithsonian Institution, Washington, DC 20013-7012, USA

${ }^{3}$ DataLab: Data Science and Informatics, 1 Shields Ave, University of California, Davis CA 95616 USA.

4,8 Åbo Akademi University, Environmental and Marine Biology, Artillerigatan 6, 20520 Åbo, Finland

${ }^{5}$ Department of Biology, San Francisco State University, San Francisco, CA 94132, USA

${ }^{6}$ Département des sciences fondamentales \& Québec-Océan, Université du Québec à Chicoutimi, Chicoutimi (Québec), G7H 2B1, Canada.

${ }^{7}$ Institute of Marine Sciences, University of North Carolina at Chapel Hill, Morehead City, NC 28557, USA

${ }^{9}$ Facultad de Ciencias, UABC, Km. 103 Carretera Tijuana - Ensenada, Ensenada, Baja California C.P. 22860, Mexico

${ }^{10}$ Fisheries Research Agency, 739-0452 Hiroshima, Japan

${ }^{11}$ Geomare AC, Paseo del Pedregal No. 82, Ensenada, Baja California 22860, Mexico

${ }^{12}$ Sveučilište u Zadru, Pomorski odjel, 23000 Zadar, Croatia

${ }^{13}$ Department of Biology, Pusan National University, Pusan 609-735, Korea

${ }^{14}$ Akkeshi Marine Station, Field Science Center for Northern Biosphere, Hokkaido University, Aikappu, Akkeshi, Hokkaido 088-1113, Japan

${ }^{15}$ Queen's University Belfast, School of Biological Sciences, 97 Lisburn Road, N. Ireland, UK

${ }^{16}$ ECOSEAS laboratory, Université de la Cote d'Azur, CNRS, Nice, France

${ }^{17}$ Department of Biology, University of Washington, Seattle, WA 98195, USA

${ }^{18}$ IMEDEA (UIB-CSIC), C/ Miquel Marques 21, 07190, Esporles, Islas Baleares, Spain

${ }^{19}$ Department of Fisheries and Wildlife, Oregon State University, Corvallis, Oregon 97331, USA

*Corresponding author: khovel@sdsu.edu

This article is protected by copyright. All rights reserved 


\section{Abstract}

Human activities degrade and fragment coastal marine habitats, reducing their structural complexity and making habitat edges a prevalent seascape feature. Though habitat edges frequently are implicated in reduced faunal survival and biodiversity, results of experiments on edge effects have been inconsistent, calling for a mechanistic approach to the study of edges that explicitly includes indirect and interactive effects of habitat alteration at multiple scales across biogeographic gradients. We used an experimental network spanning 17 eelgrass (Zostera marina) sites across the Atlantic and Pacific oceans and the Mediterranean Sea to determine (i) if eelgrass edges consistently increase faunal predation risk, (ii) whether edge effects on predation risk are altered by habitat degradation (shoot thinning), and (iii) whether variation in the strength of edge effects among sites can be explained by biogeographical variability in covarying eelgrass habitat features. Contrary to expectations, at most sites, predation risk for tethered crustaceans (crabs or shrimps) was lower along patch edges than in patch interiors, regardless of the extent of habitat degradation. However, the extent to which edges reduced predation risk, compared to the patch interior, was correlated with the extent to which edges supported higher eelgrass structural complexity and prey biomass compared to patch interiors. This suggests an indirect component to edge effects in which the impact of edge proximity on predation risk is mediated by the effect of edges on other key biotic factors. Our results suggest that studies on edge effects should consider structural characteristics of patch edges, which may vary geographically, and multiple ways that humans degrade habitats.

Key words: edge effects, habitat structure, patch, predation, seagrass, seascape ecology, structural complexity, Zostera marina

\section{Introduction}

Foundation species form critical refuge and foraging habitats for fauna throughout the world's ecosystems, and in doing so contribute substantially to biodiversity and the maintenance of key species interactions (Ellison et al. 2012). However, ecosystem functions provided by foundation species, particularly the provision of refuge from predators, can be altered by changes in habitat structure that occur across multiple spatial scales. Within individual habitat patches, thinning or 
flattening reduces the structural complexity of biogenic structures (e.g., trees, grasses, coral heads, or salt marsh stems), which may strongly influence refuge value (Alvarez-Filip et al. 2009). At landscape scales, habitat loss and fragmentation reduce connectivity and create more edges between structured and unstructured habitat. Patch edges often directly elevate faunal predation risk via high rates of predator visitation to edges (Andrén 1994), but syntheses have suggested that "edge effects" are highly variable among species, sites and habitat types (Murcia 1995, Lahti 2001, Ries et al. 2004, Gross et al. 2018). Edges also may indirectly affect predation risk because predator-prey encounter rates depend strongly on habitat structural complexity, rates of disturbance, and prey density or biomass, all of which frequently vary with edge proximity (Gates and Gysel 1978, Mills 1995, Ruffell and Didham 2016). Few studies have tested how factors that vary with edge proximity alter edge effects on ecological processes, or account for their variability. Simultaneously, experiments on the effects of structural complexity loss on fauna are common, but it is less clear by what mechanisms changing complexity influences fauna, specifically how loss of structural complexity indirectly alters relationships between ecological processes and the biotic and abiotic features of habitats, including patch edges (Harper et al. 2005). These gaps have hampered development of a comprehensive theory for the effects of habitat structure on predator-prey interactions (Kovalenko et al. 2012).

In marine ecosystems, refuge for juvenile fishes and invertebrates increases with the amount of structural complexity that habitats such as coral reefs, seagrasses, kelp forests, marshes, and bivalve reefs add to the seafloor (Heck and Crowder 1991, Kovalenko et al. 2012, Lefcheck et al. 2019). Physical and biological processes frequently fragment these habitats into discrete patches, making habitat edges prominent features of coastal biogenic seascapes. The close proximity of these habitats to human populations promote loss of structural complexity and increasing patchiness due to eutrophication, physical disturbance, sedimentation, and direct and indirect effects of fishing (Orth et al. 2006). These trends are likely to be exacerbated by global climate change due to the limited tolerances of many foundation species to rising ocean temperature and acidification (Doney et al. 2012). Thus, maintenance of key ecosystem functions in coastal marine habitats will be increasingly challenged by the combined effects of local- and global-scale impacts that degrade habitat structure.

We used a comparative-experimental approach spanning over 30 degrees of latitude and several oceanic provinces to determine the effects of habitat degradation (structural complexity loss)

This article is protected by copyright. All rights reserved 
and patch edge proximity on faunal predation risk in a widespread but heavily impacted marine habitat, eelgrass (Zostera marina). The comparative-experimental approach, in which the same experimental methodology is applied within the same habitat type simultaneously across distinct sites, allowed us to control for many sources of variability that may cause much of the inconsistency in edge effects (and other habitat features) among studies. Patchiness and distinct edges delineating structured habitat from unvegetated sediment are common features of seascapes formed by eelgrass and other seagrass species (Appendix S1: Fig. S1). Eelgrass edges are formed naturally by hydrodynamic scouring, bioturbation, grazing, and variability in sunlight and sediment chemistry (Fonseca and Bell 1998) but are increasingly the product of anthropogenic processes occurring along urbanized coastlines (Orth et al. 2006). Moreover, biotic factors that strongly influence predation risk, including structural complexity and faunal density, often vary with proximity to eelgrass patch edges (Bologna and Heck 1999, Moore and Hovel 2010), making eelgrass an ideal experimental model system in which to address questions about direct and indirect effects of patch edges on ecological processes.

We took advantage of biogeographic variability in eelgrass structural complexity and faunal community structure among 17 eelgrass communities spread across the coastlines of North America, Europe, and Asia (Fig.1; Appendix S1: Table S1) to determine (i) if eelgrass edges consistently increase faunal predation risk compared to patch interiors, (ii) whether edge effects on predation risk are altered by habitat degradation (shoot thinning), and (iii) whether variation in the strength of edge effects among sites can be explained by biogeographical variability in covarying eelgrass habitat features.

\section{Methods}

Our work involved field-based predation assays and surveys in eelgrass habitat spanning much of the biogeographic range of Z. marina, which is found along temperate to polar coastlines throughout the Northern Hemisphere. We used tethering to determine relative predation risk for locally collected organisms along patch edges and in patch interiors under three levels of experimental eelgrass degradation $(0,50$, and $80 \%$ shoot loss $)$ in a crossed design. Tethering measures the relative mortality rate of prey among different treatments and represents risk for prey that are readily available to predators (Aronson \& Heck 1995). Tethered prey at each site consisted of a locally collected 
mesopredator species (juvenile shrimp, crab, or fish) commonly found in the guts of higher consumers (Appendix S1: Table S1). We chose to allow prey type to vary among sites (rather than standardizing prey among sites) in order to provide a relevant measure of predation risk and edge effect strength at each site. We used our observations and (where available) data on predator gut contents and prey choice to ensure that taxa selected for tethering were similarly vulnerable to higher-order consumers.

Our experiments were conducted within an approximately eight week window (15 June to 15 August) in the summer of 2015. To conduct experiments, at each site we first selected a large eelgrass bed (typically $\left.>5,000 \mathrm{~m}^{2}\right)$ in shallow water $(0.5-1.5 \mathrm{~m}$ water depth at low tide) with a distinct edge formed by an abrupt transition from eelgrass to unvegetated sand or mud. Eelgrass edges used for the experiment at each site were always submerged (i.e. we avoided edges that were exposed at low tides) and at least $5 \mathrm{~m}$ away from any other structured habitat. Edge habitat was defined as being within eelgrass but within $1 \mathrm{~m}$ of the transition from eelgrass to unvegetated sediment, and interior habitat was $>5 \mathrm{~m}$ from this transition. We chose these distances because, in seagrass, habitat edge effects on mortality and abundance of small epifauna typically occur within $1 \mathrm{~m}$ of patch edges (Tanner 2005, Macreadie et al. 2010). Patch vegetation consisted exclusively of eelgrass, except for epibionts or sparse drift algae. At each site we created 21 experimental 1-m x 1-m plots along the edge and 21 identical plots within the interior of the eelgrass bed. To create habitat degradation treatments, we randomly selected seven of the 21 plots at the edge and in the interior, and after obtaining shoot counts within these plots, haphazardly pulled shoots by hand to thin each plot to $50 \%$ of its ambient shoot density, creating 50\% habitat degradation plots. We thinned another seven randomly selected plots to $20 \%$ ambient shoot density ( $80 \%$ habitat degradation plots) along both the edge and interior of the bed, while the remaining seven plots along the edge and within the interior remained at ambient shoot density.

Each tether consisted of a single $10 \mathrm{~cm}$-long piece of monofilament (Fireline ${ }^{\mathrm{TM}}$; dia. $0.13 \mathrm{~mm}$ ) tied near the top of $40 \mathrm{~cm}$ clear acrylic rod. We used cyanoacrylate glue to affix one individual prey organism to each tether, and held tethered organisms in running seawater overnight before deploying each to the center of a randomly chosen plot the next day (one tethered organism per plot per trial). Organisms were deployed adjacent to at least one eelgrass shoot and were free to cling to the base of shoots or rest upon the sediment surface. We kept tethers short to prevent tangling around seagrass 
shoots, because tangling can lead to treatment-specific bias (e.g., if tangling is more likely to happen in dense than in sparse seagrass). However, it is possible that some mortality in our study was due to predators that normally would not be able to consume the species we selected, due to limited prey mobility from short tethers. We suspect this was minimal, as the species we chose to tether at each site generally rely on crypsis to avoid predators. Trials lasted $24 \mathrm{~h}$, at which time we retrieved acrylic rods and scored each individual as alive, eaten (fragments of the carapace remaining on tether), missing, or molted (entire carapace remaining on tether). We considered organisms that went missing to have been consumed by predators because no organisms tethered in predator-free controls at three sites ( $\mathrm{n}=20$ each at Bodega Bay, Finland, and San Diego) fell off tethers after $48 \mathrm{~h}$. Few animals molted on tethers, and any that did were removed from the analysis. Four trials of the experiment were conducted over a $7-10$ day period at each site $(N=7$ individuals per treatment per trial * 6 treatments $* 4$ trials $=168$ organisms tethered per site).

Immediately after trials concluded we sampled all plots within the eelgrass bed at each site to quantify how factors that commonly affect faunal predation risk vary with proximity to the patch edge. This included two measures of habitat structural complexity (eelgrass shoot density, and the biomass of epibionts, which are algae and sessile invertebrates that add structure by colonizing shoots), as well as the biomass of canopy-dwelling epifauna. To quantify structural complexity, we (i) obtained eelgrass shoot density by counting shoots within $1 \mathrm{~m}^{2}$ plots (for sites with low shoot density) or within smaller $314 \mathrm{~cm}^{2}$ quadrats (for sites with shoot densities above 100 shoots $\mathrm{m}^{-2}$ ); and (ii) quantified epibiont biomass by scraping all epiphytic algae and sessile epifauna from three haphazardly selected shoots from each plot. Scraped epibionts and eelgrass shoots were dried at $60{ }^{\circ} \mathrm{C}$ in a drying oven and weighed to calculate epibiont biomass per unit eelgrass biomass (hereafter “epibiont biomass"). To quantify the biomass of canopy-dwelling epifauna we placed a $25 \mathrm{~cm}$ diameter, $0.5 \mathrm{~mm}$ mesh bag over eelgrass in a haphazardly selected area of each plot and cut eelgrass at the sediment surface to collect above-ground material. This technique efficiently captures relatively small seagrass epifauna (e.g., amphipods, isopods, gastropods, small shrimp and crabs), but undersamples larger, mobile epifauna (e.g. larger shrimp and crabs, and fishes). In the laboratory we rinsed mesh bags and shoots to remove epifauna, separated crustaceans from other taxa (primarily gastropods), and dried crustaceans and shoots to calculate crustacean biomass per unit eelgrass

This article is protected by copyright. All rights reserved 
biomass (hereafter "crustacean biomass") which we used in statistical models to represent the availability of alternative prey surrounding tethered organisms. We chose to use crustacean biomass rather than total epifaunal biomass in analyses because our tethered prey were crustaceans (except at one site), and because a previous study found that in eelgrass, predation rates were far lower for gastropods than for crustaceans (Reynolds et al. 2018). Additionally, exploratory analyses including gastropod biomass revealed no evidence for effects on predation risk or edge effect strength. Data analysis

Predation risk within sites. We first assessed biogeographic variability in the interactive effects of habitat degradation treatment, edge proximity treatment, structural complexity (shoot density and epibiont biomass), and crustacean biomass on predation risk (i.e., the odds of being consumed). At each site we used a model comparison approach to assess the relative strength of 10 competing generalized linear models (GLMs) that included different combinations of predictor variables (Burnham and Anderson 2002; Table 1). Specifically, we evaluated the fit of a full model (M1) that included an interactive effect of habitat degradation and edge proximity on the odds that tethered fauna would be consumed, as well as effects of shoot density, epibiont biomass, and crustacean biomass. We compared this model to simpler models that excluded one or more continuous variables (M2 - M6), a model that removed the interaction between habitat degradation and edge proximity (M7), and models with only edge proximity (M8) or habitat degradation (M9) as factors. To test for overall significance, we compared all models to a null model with no predictors (M10). We compared models using Akaike's Information Criterion corrected for sample size bias (AICc), delta-AICc (a measure of the strength of evidence of each model relative to the best model, which has the lowest AICc value: $\Delta \mathrm{i}=\mathrm{AICc}, \mathrm{i}-\mathrm{AICc}, \mathrm{min}$ ), and $\mathrm{AIC}$ weights ( $w_{i}$, the probability that model $\mathrm{i}$ is the best fitting model). We ranked models at each site using $\Delta \mathrm{i}$ and $w_{i}$ and considered $\Delta \mathrm{i}<$ 2 to indicate substantial model support (Burnham and Anderson 2002). Using the output from the models with strong support, we calculated odds ratios and 95\% confidence intervals (CIs) to assess predation risk effect size and variability for predictors. Odds ratios specify how the odds of being consumed change when comparing one treatment to another (e.g., the odds of being consumed in $50 \%$ shoot loss plots vs. ambient plots, or at the edge vs. the interior), or how the odds of being consumed change with a unit change in a continuous predictor variable (e.g., for each additional gram of 
crustacean biomass). We treated CIs as "compatibility intervals" (sensu Amrhein et al. 2019) when judging the strength of treatment effects (see also Burnham and Anderson 2014). Continuous variables were $\log _{10}$ transformed to improve normality, and data were pooled among trials before analyses.

Variability in edge effect strength among sites. We next evaluated what factors explain differences among sites in the strength of edge effects on predation risk (hereafter "edge effect strength"). Specifically, we asked whether edge effect strength is correlated with edge-vs.-interior differences in shoot density, epibiont biomass, and crustacean biomass among sites, and whether the significance of these relationships depends on the level of habitat degradation. For each level of habitat degradation at each site, we (i) used edge-vs.-interior odds ratios for predation risk, generated from site-level GLMs described above, to represent edge effect strength; and (ii) generated an edgeto-interior effect size for shoot density, epibiont biomass, and crustacean biomass by calculating the $\log$ response ratio (LRR) for each variable. The LRR is a dimensionless measure of effect size calculated by taking the natural log of the ratio of two means, and is widely used as a measure of effect size for measurements on a physical scale (Hedges et al. 1999). We then used linear mixedeffect models (with site as a random term) to test whether the edge effect strength depends on edgevs.-interior effect sizes for shoot density, epibiont biomass, and crustacean biomass, and their interactions with habitat degradation. Specifically, we used AIC, $\Delta \mathrm{i}$, and $w_{i}$ to evaluate the fit of eight competing models (Appendix S1: Table S2). We also tested models that included ocean basin (Atlantic and Mediterranean vs. Pacific), taxon (shrimp vs. crab), and size of tethered organisms as factors, but models including these factors had substantially worse model fits, and visualization indicated no effects of these factors on edge effect strength. Thus, these factors were not considered further. Our initial models included latitude as an explanatory factor, but its inclusion raised model AIC values, and as a single factor latitude was not a strong predictor of edge effect strength $\left(\mathrm{r}^{2}=0.04\right.$, $P=0.15)$. Latitude therefore was not included in final models. We visually assessed data for normality and homogeneity of variance, and determined that edge-vs.-interior effect size for shoot density, epibiont biomass, and crustacean biomass were not correlated with one another before running tests (Pearson correlations: all $\mathrm{r}$ values $<0.3$ ).

This article is protected by copyright. All rights reserved 
Variability in habitat degradation effect strength among sites. Lastly, we asked what factors explain differences among sites in the strength of habitat degradation effects on predation risk. Specifically, we tested whether habitat degradation effects on predation risk among sites are correlated with the size of the effect of habitat degradation on crustacean biomass and on epibiont biomass, and with ambient shoot density at each site. In two separate analyses, we used a response variable defined by the odds ratio of predation risk between ambient plots and those with each level of degradation. Accordingly, we included as predictor variables the log response ratios of crustacean biomass and epibiont biomass between ambient plots and those with each level of degradation, as well as ambient shoot density (Appendix S1: Table S3). We used AICc, $\Delta \mathrm{i}$, and $w_{i}$ as described above to compare the full model to simplified models and a null model. Initial models including ocean basin, taxon, and organism size as factors provided poor fits to the data and thus were not considered further.

All analyses were performed using the MASS, lme4, and MuMin packages in R version 3.5.2 ( $\mathrm{R}$ core team 2018).

\section{Results}

Predation risk within sites. Models M1 - M5, which included shoot density, epibiont biomass, and crustacean biomass within the plot as predictors, had extremely poor fits at all 17 sites (all $w_{i}<$ 1\%). M6, which included an interactive effect of habitat degradation and edge proximity, also fit poorly at all sites (all $w_{i}<3 \%$ ). This leads to two important conclusions: first, shoot density, epibiont biomass, and prey biomass had few direct effects on predation risk; and second, habitat degradation did not affect relative predation risk along the patch edge compared to the patch interior.

Overall, proximity to the edge of the seagrass patch was the most influential predictor for predation risk (Appendix S1: Fig. S2). M8, in which proximity to the edge was the only predictor variable, was the best fitting model at seven sites, had substantial support $(\Delta \mathrm{i}<2)$ at all but one site (Mexico), and had the highest average support of all models ( $\left.\overline{\mathrm{x}} w_{i}=42.7 \%+6.8 \mathrm{SE}\right)$. The null model (M10) was the best fitting model at seven sites $\left(\overline{\mathrm{x}} w_{i}=27.1 \%+5.0\right)$, however, a competing model (M7, M8, or M9) also had substantial support at all but one of these sites (Mexico). Habitat degradation had relatively little influence on predation risk. M7 and M9, both of which included habitat degradation as a predictor, had substantial support at six sites, but were the best fitting model

This article is protected by copyright. All rights reserved 
at only one (Korea B) and two (France and Virginia) sites, respectively, and had low support overall ( $\mathrm{x} w_{i}=13.4 \%+3.1$ and $15.4 \%+4.2$ for M7 and M9, respectively).

Focusing on individual sites, we also found significant edge effects on predation risk (i.e., CIs for point estimates did not overlap a value of one) at 10 out of 17 sites, and edges were less risky than patch interiors for tethered prey at most of these sites (Fig. 2). Predation risk was on average 2.4 times higher in the patch interior than along the patch edge at Bodega Bay, Finland, France, Korea B, Northern Ireland, San Diego, and San Francisco, but was on average 2.04 times higher along the edge than in the patch interior at Japan North, Japan South, and Quebec (Fig. 2). Point estimates suggested that predation risk also was higher in the patch interior than along the edge in Oregon, Korea A, and Virginia, and higher along the edge than in the patch interior at Croatia, though CIs at these sites overlapped a value of one, so we were unable to distinguish whether edges increased, decreased, or did not strongly affect predation risk. At the remaining three sites (Mexico, North Carolina, and Washington), point estimates were very close to a value of one, suggesting negligible effects of edges on predation risk.

Overall we found small or variable effects of habitat degradation on predation risk, corroborating results of model comparisons. In the $50 \%$ habitat degradation treatment, CIs overlapped a value of one at all but the two sites in Korea, suggesting that at most sites, habitat degradation could increase, decrease, or have no effect on predation risk (Fig. 2). At Korea A and B, the odds of being eaten were $140 \%$ higher in ambient plots compared to $50 \%$ habitat removal plots. Point estimates for the $80 \%$ habitat degradation treatment suggested an increase in predation risk with degradation at 11 out of 16 sites (in North Carolina there were not enough organisms remaining alive to calculate odds ratios for habitat degradation). However effect sizes varied widely among sites (range 3\% to 291\% increase in odds of being consumed) and all CIs for odds ratios overlapped a value of one.

The effects of edge proximity on eelgrass shoot density, epibiont biomass, and crustacean biomass were highly variable in strength and direction among sites (Appendix S1: Fig. S3). Thus, habitat features that may influence predation risk commonly covary with edge proximity, but in different ways among sites.

Variability in edge effect strength among sites. The best fitting model explaining edge effect strength $\left(w_{i}=54.5 \% ; \mathrm{F}_{7,40}=4.5, P<0.001, \mathrm{r}^{2}=0.44\right)$ was the full model that included (i) habitat 
degradation, (ii) an interactive effect of habitat degradation and edge-vs.-interior effect size for crustacean biomass, and (iii) edge-vs.-interior effect sizes for shoot density and for epiphyte biomass (Fig. 3; Appendix S1: Table S2). Of these terms, edge-vs.-interior effect size for shoot density explained the highest proportion of the variance in edge effect strength: predation risk was higher at patch edges (compared to patch interiors) at sites with lower shoot density along patch edges. Additionally, in the ambient treatment (no habitat degradation), sites with lower levels of crustacean biomass at patch edges had elevated predation risk at patch edges. This effect was not present in the $50 \%$ or $80 \%$ habitat degradation treatments. Edge effect strength also decreased with edge-vs.-interior effect size for epibiont biomass, though this term explained a smaller proportion of the variability than other terms. There was a weak trend for edge effect strength to increase with habitat degradation: on average, patch interiors were slightly riskier than patch edges in ambient plots, but this trend was not present in degraded plots.

Variability in habitat degradation effect strength among sites. Variability in the effect of habitat degradation on predation risk among sites was not explained by differences in crustacean biomass or epiphyte biomass among treatments, or by ambient shoot densities at sites. The null model was the best fitting model for predation risk at both $50 \%$ and $80 \%$ degradation relative to ambient, and no competing models had strong support (Appendix S1: Table S3).

\section{Discussion}

Accelerating degradation and fragmentation of coastal marine habitats makes it imperative to determine how changing habitat structure and configuration influence ecological processes, and by what mechanisms. Provision of refuge from predation is a chief ecosystem function of vegetated aquatic habitats. We tested for interactive effects of experimental habitat degradation (loss of structural complexity) and patch edge proximity on epifaunal predation risk in eelgrass communities at 17 sites spread across the Atlantic and Pacific oceans and the Mediterranean Sea. We found that proximity to the edge of a seagrass patch had larger effects on predation risk than did habitat degradation within patches, and that habitat degradation did not alter effects of edge proximity on predation risk. Edge effects varied in strength and direction among sites, but edges were less risky than patch interiors for fauna at most sites. Among sites, riskier edges tended to be those with low

This article is protected by copyright. All rights reserved 
shoot density and epibiont biomass, and (in non-degraded conditions) low crustacean biomass compared to patch interiors. This suggests an indirect component to edge effects in which the impact of edge proximity on predation risk is mediated by the effect of edges on key biotic factors: i.e., because the effect of edges on biotic factors varies among sites, so too does the effect of edges on predation risk.

Our results contrast with research showing that patch edges have elevated predation risk compared to patch interiors, including many studies in seagrass habitat that found elevated mortality rates for prey along patch edges relative to patch interiors (e.g., Irlandi et al. 1995, Bologna and Heck 1999, Gorman et al. 2009, Smith et al. 2011, Carroll et al. 2012, Mahoney et al. 2018). However, our results are in accordance with recent syntheses and empirical results suggesting that edge effects vary widely in direction and magnitude, even within the same habitat type, both on land (Debinski and Holt 2000, Lahti 2001, Ries et al. 2004) and in the sea (Boström et al. 2006, Selgrath et al. 2007, Carroll et al. 2012). Several factors may contribute to this variability by influencing the density, behavior, or efficiency of predators, though these factors have rarely been tested (Ruffell et al. 2014). These include differences in the structural and spatial characteristics of habitats (i.e. landscape or seascape context: e.g. Donovan et al. 1997), the degree of contrast between two adjacent habitats (i.e. edge type), and time since edge creation (Gieselman et al. 2013, reviewed by Harper et al. 2005).

Edge effect strength and direction also may depend on the degree to which biotic and abiotic factors differ between patch edges and interiors. These indirect effects of edges occur when habitat features, or disturbances to habitat, vary with proximity to an edge and dictate the strength of interactions occurring within the patch (Ruffell and Didham 2016). For instance, vegetation structure increased with distance from the edge of Australian forest patches, which in turn increased the abundance of invasive ship rats (Rattus rattus) that prey upon on bird nestlings, and this effect was mediated by the amount of disturbance by grazing cattle (Ruffell et al. 2014). Indirect effects of edges likely are widespread, though they are seldom studied, in part because quantifying indirect effects by experimentally controlling for factors such as habitat structure or prey density is intractable in many habitat types (but see Macreadie et al. 2010, Villaseñor et al. 2015). Additionally, most studies on edge effects do not take place over large enough spatial scales to encompass the biogeographic variability in habitat features needed to address indirect mechanisms.

This article is protected by copyright. All rights reserved 
The strength of edge effects on predation risk was highly variable across the range of eelgrass in our study, and this variability was partly explained by variation in the physical and community structure of the patch edge. Specifically, compared with patch interiors, edges with low shoot density and low crustacean biomass tended to have higher predation risk. Increasing structural complexity commonly reduces faunal predation risk because structural elements of habitat can interfere with predator search and capture (Heck and Crowder 1991, Kovalenko et al. 2012). In particular, dense eelgrass may restrict the movement and field-of-view for predators (Bartholomew et al. 2000), and epibionts that colonize seagrass shoots, particularly filamentous algae, may contribute to lower predator detection of prey (Hovel et al. 2016). Together, shoot density and epibiont biomass contributed to a large fraction of the variability in edge effect strength among sites in our study. The fact that edges containing higher crustacean biomass than patch interiors tended to have lower predation risk may reflect lower predator abundance along edges, or alternatively, increasing crustacean biomass may decrease per capita predation risk by diluting risk among individuals (Mattila et al. 2008).

Our results suggest that differences in structural complexity between patch edge and interior, and perhaps crustacean biomass, contributed to the strength and direction of edge effects on predation risk. But edges also can more directly influence predation risk by influencing predator habitat selection and predator-prey encounter rates. Recent censuses of fish communities within seagrass habitat suggest that juvenile or adult fishes (common predators on small fauna) often may be associated with more contiguous seagrass habitat that contains fewer edges (Staveley et al. 2017, Yeager et al. 2016) or larger patches with lower edge to interior ratios (Laurel et al. 2003). This corresponds to the overall trend for riskier patch interiors than patch edges in our study. In San Diego, where predation risk was significantly higher in the patch interior than along the edge, juvenile fishes of several species are abundant within eelgrass patch interiors and have diets consisting largely of crustaceans (Moore and Hovel 2010). Sites with no edge-vs.-interior differences in predation risk may be characterized by more uniform distributions of dominant fishes across meadows, such as red drum (Sciaenops ocellatus) and pinfish (Lagodon rhomboides) in North Carolina (Mahoney et al. 2018), or staghorn sculpin (Leptocottus armatus) in Washington and Oregon (Hayduk et al. 2019, Ruesink et al. 2019). Furthermore, the higher risk for epifauna along seagrass patch edges at some sites may be 
explained by large predators using unvegetated areas as corridors that facilitate movement through benthic seascapes (Irlandi et al. 1995), or moving to seagrass habitat from other habitats to forage (Gorman et al. 2009, Smith et al. 2011). At our Japan South site, large fish predators such as adult rockfish (Sebastes spp.) move from adjacent sand flats to vegetated habitats at night to forage, and in doing so encounter prey first along patch edges (see Kinoshita et al. 2012). Likewise, at Japan North, we observed large flatfishes such as cresthead flounder (Pleuronectes schrenki) moving from deeper, adjacent sand flats to eelgrass beds to forage on tethered grass shrimp.

An important finding from our study is that proximity to patch edges had stronger effects on mortality risk than did habitat degradation: even though differences in structural complexity between patch edges and interiors may have helped dictate the strength of edge effects, the removal of 50 $80 \%$ of seagrass above-ground structure had highly variable, but often small effects on mortality risk at each site (Fig.2). This was surprising, as we expected strong and consistent increases in predation risk with habitat degradation based on the idea that structurally complex habitats provide refuge for fauna by reducing predator-prey encounter rates. How changes to structural complexity affect prey risk ultimately depends on how these changes affect predator behavior and distribution. For instance, degradation can reduce rather than increase predator-prey encounter rates if predators avoid areas of low structural complexity, which may occur if higher-order predators pose a risk to them (e.g., Micheli 1997, Mahoney et al. 2018). Our finding that effects of degradation on predation risk can vary widely among sites, and can be positive or negative, likely reflects the variability in the type and abundance of mid- and top-level predators among sites. Alternatively, it is possible that our degraded plots were not large enough to affect the behavior of some predators, given that plots were embedded within larger eelgrass patches in which structural complexity remained unchanged. In previous studies, however, manipulations of eelgrass structural complexity over much smaller spatial extents (e.g. $0.05 \mathrm{~m}^{2}$; Hovel and Lipcius 2001) altered the outcome of predator-prey interactions in eelgrass habitat.

We also found that habitat degradation had little influence on whether patch edges were riskier than patch interiors at individual sites. Habitat degradation might be expected to reduce edge-vs.interior differences in predation risk if degradation has an overwhelming effect on predator behavior and predator-prey encounter rates (if, for instance, predators are much more efficient at finding prey 
within degraded patches, regardless of their proximity to an edge; Mahoney et al. 2018). The only strong effect of habitat degradation that we found was that the inverse correlation between edge effects on crustacean biomass and the strength of edge effects on predation risk disappeared when eelgrass was degraded. We did not observe reduced variability in edge effect size for crustacean biomass in degraded plots, suggesting the alternative explanation that habitat degradation may have led to edge-to-interior differences in the type or behavior of alternative prey available in plots, or the type or behavior of predators that entered plots in search of prey.

Several caveats apply to our findings. First, our experiments were conducted during a narrow window of time in the summer, when eelgrass generally reaches peak biomass and shoot length. However, eelgrass structural complexity and seascape structure can change seasonally, particularly in southern locations that typically undergo above-ground defoliation when water temperatures peak in late summer, and this can alter seagrass effects on predator-prey relationships (Hovel and Lipcius 2002). For instance, in North Carolina, seasonal increases in water temperature increased crab relative mortality in continuous seagrass but not in fragmented seagrass, though edge effects on crab relative mortality were unchanged (Yarnall and Fodrie 2020). Thus, our findings may have differed if we had performed our experiments at other times of the year. Second, we tested for edge effects on predation risk by making edge-vs.-interior comparisons, rather than using a continuum of distances from seagrass patch edges. However, our approach is appropriate for eelgrass habitat because the distance to which edge effects penetrate into seagrass habitat often is very small $(<1 \mathrm{~m}$ : Tanner 2005 , Macreadie et al. 2010). Third, we did not standardize tethered prey among sites because our goal was to determine how edge proximity affects predation risk for relevant mesopredators across the Northern Hemisphere. Though the species we selected for tethering all are common prey items for higher-order predators, using standardized prey may have resulted in more similar effects of edges and habitat degradation on predation risk among sites. Finally, we were able to examine only a small number of potential causes of variability in edge effects and predation risk. Patterns were markedly different among our sites, and we were not able to explain the causes of much of this variability. For instance, despite careful selection of similar eelgrass patches and edges among sites, many aspects of seascape structure (e.g. nearest neighbor distance and seascape composition) and related factors (e.g. hydrodynamic activity, which influences patchiness) varied from site to site, which may have 
influenced the type and behavior of predators attacking our tethered prey (see also Yeager et al. 2012, 2016). Future seascape-scale studies would benefit from explicitly considering factors that covary with edge proximity and patchiness. In particular, there is a need for more information on how biotic and abiotic covariates of edge proximity (e.g. animal abundance, different components of structural complexity, and disturbances by hydrodynamic activity and other factors) influence distribution and behavior of a range of predator and prey species and associated organisms within food webs.

In conclusion, our results provide evidence that the effects of habitat patch edges on faunal predation risk can vary widely in direction and strength, and suggest that structural complexity of the patch edge may play a large role in determining how edges alter predator-prey relationships.

Determining how factors like patch edges and habitat degradation affect faunal predation risk is important not only to better understand the consequences of habitat alteration on population dynamics and ecological interactions, but also due to increasing evidence that top-down processes directly affect the health and persistence of seagrasses (Whalen et al. 2013, Reynolds et al. 2014) and other coastal habitats such as coral reefs (Mumby et al. 2006). Strategies for restoring degraded seagrass habitat may differ depending on whether ecosystem services (nursery habitat provision, carbon and contaminant sequestration, enhanced secondary production, shoreline protection, and others) are more closely tied to edge proximity or to structural complexity, or to other factors. Thus, determining the interplay of factors that control predation risk for fauna, particularly in degraded conditions that are increasingly common in seagrasses, is a key step in sustaining the suite of ecosystem services these habitats provide.

\section{Acknowledgments}

We thank the many lab and field assistants that participated in this research and whose contributions of time and effort were invaluable for making this project happen. Comments from two anonymous reviewers strengthened the manuscript. This research was funded by National Science Foundation grants to JED, JJS, and KAH (NSF-OCE 1336206, OCE 1336905, OCE 1336741). CB was funded by the Åbo Akademi University Foundation. This is contribution number 73 from the Coastal and Marine Institute at San Diego State University.

This article is protected by copyright. All rights reserved 


\section{Supporting Information}

Additional supporting information may be found online at: [link to be added in production]

\section{Data Availability}

R script and data files are available on Zenodo (Hovel 2020): https://doi.org/10.5281/zenodo.4313621

\section{References}

Alvarez-Filip, L., N.K. Dulvy, J.A. Gill, I.M. Cote, and A.R. Watkinson. 2009. Flattening of Caribbean coral reefs: region-wide declines in architectural complexity. Proceedings of the Royal Society B 276: 3019-3025.

Amrhein, V., S. Greenland, and B. McShane. 2019. Scientists rise up against statistical significance. Nature 567: 305-307.

Andrén, H. 1994. Effects of habitat fragmentation on birds and mammals in landscapes with different proportions of suitable habitat: a review. Oikos 71: 355-366.

Aronson, R.B., and K.L. Heck Jr. 1995. Tethering experiments and hypothesis testing in ecology. Marine Ecology Progress Series 121: 307-309.

Bartholomew, A., R.J. Diaz, and G. Cicchetti. 2000. New dimensionless indices of structural habitat complexity: predicted and actual effects on a predator's foraging success. Marine Ecology Progress Series 206: 45-58.

Bologna, P.A.X., and K.L. Heck Jr. 1999. Differential predation and growth rates of bay scallops within a seagrass habitat. Journal of Experimental Marine Biology and Ecology 239: 299-314.

Boström, C., E.L. Jackson, and C.A. Simenstad. 2006. Seagrass landscapes and their effects on associated fauna: A review. Estuarine, Coastal, and Shelf Science 68: 383-403.

Burnham K.P., and D.R. Anderson. 2002. Model selection and multimodel inference: a practical information-theoretic approach, 2nd ed. Springer, New York.

Burnham, K.P., and D.R. Anderson. 2014. P values are only an index to evidence: $20^{\text {th }}-$ vs. $21^{\text {st }}$ century statistical science. Ecology 95: 627-630. 
Carroll, J.M., B.T. Furman, S.T. Tettelbach, and B.J. Peterson. 2012. Balancing the edge effects budget: bay scallop settlement and loss along a seagrass edge. Ecology 93: 1637-1647. https://doi.org/10.1890/11-1904.1

Debinksi, D., and R. Holt. 2000. A survey and overview of habitat fragmentation experiments. Conservation Biology 14:342-355.

Doney, S.C., M. Ruckelshaus, J.E. Duffy, J.P. Barry, F. Chan, C.A. English, H.M. Galindo, J.M. Grebmeier, A.B. Hollwed, N. Knowlton, J. Polovina, N.N. Rabalais, W.J. Sydeman, and L.D. Talley. 2012. Climate change impacts on marine ecosystems. Annual Review of Marine Science 4: 11-37.

Donovan T.M., P.W. Jones, E.M. Annand, and F.R. Thompson III. 1997. Variation in local-scale edge effects: mechanisms and landscape context. Ecology 78: 2064-2075.

Ellison, A.M., M.S. Bank, B.D. Clinton, E.A. Colburn, K. Elliott, C.R. Ford, D.R. Foster, B.D. Kloeppel, J.D. Knoepp, G.M. Lovett, J. Mohan, D.A. Orwig, N.L. Rodenhouse, W.V. Sobczak, K.A. Stinson, J.K. Stone, C.M. Swan, J. Thompson, B. Von Holle, and J.R. Webster. 2012. Loss of foundation species: consequences for the structure and dynamics of forested ecosystems. Frontiers in ecology and the environment 3: 479-486.

Fonseca, M.S., and S.S. Bell. 1998. Influence of physical setting on seagrass landscapes near Beaufort, North Carolina, USA. Marine Ecology Progress Series 171: 109-121.

Gates, J.E., and L.W. Gysel. 1978. Avian nest dispersion and fledgling success in field-forest ecotones. Ecology 59: 871-883.

Gieselman, T.M., K.E. Hodges, and M. Vellend. 2013. Human-induced edges alter grassland community composition. Biological Conservation 158: 384-392.

Gorman, A.M., R.S. Gregory, and D.C. Schneider. 2009. Eelgrass patch size and proximity to the patch edge affect predation risk of recently settled age 0 cod (Gadus). Journal of Experimental Marine Biology and Ecology 371: 1-9.

Gross, C., C. Donoghue, C. Pruitt, and J.L. Ruesink. 2018. Habitat use patterns and edge effects across a seagrass-unvegetated ecotone depend on species-specific behaviors and sampling methods. Marine Ecology Progress Series 598: 21-33. https://doe.org/10.3354/meps12609.

This article is protected by copyright. All rights reserved 
Harper, K.A., E. Macdonald, P.J. Burton, J. Chen, K.D. Brosofske, S.C. Saunders, E.S. Euskirchen, D. Roberts, M.S. Jaiteh, and P-A. Esseen. 2005. Edge influence on forest structure and composition in fragmented landscapes. Conservation Biology 19: 768-782.

Hayduk, J.L., S.D. Hacker, J.S. Henderson, and F. Tomas. 2019. Evidence for regional-scale controls on eelgrass (Zostera marina) and mesograzer community structure in upwelling-influenced estuaries. Limnology and oceanography 64: 1120-1134.

Heck, K.L. Jr., and L.B. Crowder. 1991. Habitat structure and predator-prey interactions. Pages 281299 in S.S. Bell, E. McCoy, H. Mushinsky, editors. Habitat complexity: the physical arrangement of objects in space. Chapman and Hall, New York New York, USA.

Hedges, L.V., J. Gurevitch, and P.S. Curtis. 1999. The meta-analysis of response ratios in experimental ecology. Ecology 80: 1150-1156.

Hovel, K.A., and R.N. Lipcius. 2001. Habitat fragmentation in a seagrass landscape: patch size and complexity control blue crab survival. Ecology 82:1814-1829.

Hovel, K.A., and R.N. Lipcius. 2002. Effects of seagrass habitat fragmentation on juvenile blue crab survival and abundance. Journal of Experimental Marine Biology and Ecology 271: 75-98.

Hovel, K.A., A.M. Warneke, S.P. Virtue-Hilborn, and A.E. Sanchez. 2016. Mesopredator foraging success in eelgrass (Zostera marina L.): relative effects of epiphytes, shoot density, and prey abundance. Journal of Experimental Marine Biology and Ecology 474: 142-147.

Hovel, K. 2020. kahovel/Code: Hovel R code for Ecology manuscript release 1 (Version v1.0). Zenodo. http://doi.org/10.5281/zenodo.4313621

Irlandi, E.A., W.G. Ambrose Jr., and B.A. Orlando. 1995. Landscape ecology and the marine environment: how spatial configuration of seagrass habitat influences growth and survival of the bay scallop. Oikos 72: 307-313.

Kinoshita, H., Y. Kamimura, K. Kirai, K. Mizuno, Y. Iwamoto, and J. Shoji. 2012. Vulnerability of juvenile fish to piscivorous fish predators increases during nighttime in a seagrass bed in the central Seto Inland Sea, Japan. Bull. Jpn. Fish. Oceanogr. 76: 24-30.

Kovalenko, K.E., S.M. Thomaz, and D.M. Warfe. 2012. Habitat complexity: approaches and future directions. Hydrobiologia 685: 1-17.

This article is protected by copyright. All rights reserved 
Lahti, D.C. 2001. The "edge effect on nest predation" hypothesis after twenty years. Biological Conservation 99: 365-374.

Laurel, B.J., R.S. Gregory, and J.A. Brown. 2003. Predator distribution and habitat patch area determine predation rates on Age-0 juvenile cod Gadus spp. Marine Ecology Progress Series 251: 245-254.

Lefcheck, J.S., B.B. Hughes, A.J. Johnson, B.W. Pfirrmann, D.B. Rasher, A.R. Smyth, B.L. Williams, M.W. Beck, and R.J. Orth. 2019. Are coastal habitats important nurseries? A meta-analysis. Conservation Letters DOI: 10.1111/conl.12645.

Macreadie, P.I., J.S. Hindell, M.J. Keough, G.P. Jenkins, and R.M. Connolly. 2010. Resource distribution influences positive edge effects in a seagrass fish. Ecology 91: 2013-2021.

Mahoney, R, M.D. Kenworthy, J.K. Geyer, K.A. Hovel, and F.J. Fodrie. 2018. Distribution and relative predation risk of nekton reveal complex edge effects within temperate seagrass habitat. Journal of Experimental Marine Biology and Ecology 503: 52-59.

Mattila, J., K.L. Heck Jr., E. Millstein, E. Miller, C. Gustafsson, S. Williams, and D. Bryon. 2008. Increased habitat structure does not always provide increased refuge from predation. Marine Ecology Progress Series 361: 15-20.

Micheli, F. 1997. Effects of predator foraging behavior on patterns of prey mortality in marine soft bottoms. Ecological Monographs 67: 203-224.

Mills, L.S. 1995. Edge effects and isolation: red-backed voles on forest remnants. Conservation Biology 9: 395-403.

Moore, E.C., and K.A. Hovel. 2010. Relative influence of habitat complexity and proximity to patch edges on seagrass epifaunal communities. Oikos 119: 1299-1311.

Mumby, P.J., C.P. Dahlgren, A.R. Harborne, C.V. Kappel, F. Micheli, D.R. Brumbaugh, K.E. Holmes, J.M. Mendes, K. Broad, J.N. Sanchirico, K. Buch, S. Box, R.W. Stoffle, and A.B. Gill. 2006. Fishing, trophic cascades, and the process of grazing on coral reefs. Science 311: 98-101.

Murcia, C. 1995. Edge effects in fragmented forests: implications for conservation. Trends in Ecology and Evolution 10: 58-62.

This article is protected by copyright. All rights reserved 
Orth, R.J., T.J.B. Carruthers, W.C. Dennison, C.M. Duarte, J.W. Fourqurean, K.L. Heck Jr., A. R. Hughes, G.A. Kendrick, W.J. Kenworthy, S. Olyarnik, F.T. Short, M. Waycott, and S.L. Williams. 2006. A global crisis for seagrass ecosystems. Bioscience 56: 987-996.

R Core Team. 2018. R: A Language and Environment for Statistical Computing (R Foundation for Statistical Computing, Vienna, Austria; https://www.R-project.org/).

Reynolds, P.L., J.P. Richardson, and J.E. Duffy. 2014. Field experimental evidence that grazers mediate transition between microalgal and seagrass dominance. Limnology and oceanography 59: 1053-1064.

Reynolds, P.L., J.J. Stachowicz. K.A. Hovel, C. Bostrom, K. Boyer, M. Cusson, J.S. Eklof, F.G. Engel, A.H. Engelen, B.K. Eriksson, F.J. Fodrie, J.N. Griffin, C.M. Hereu, M. Hori, T.C. Hanley, M. Ivanov, P. Jorgensen, C. Kruschel, K.S. Lee, K. McGlathery, P.O. Moksnes, M. Nakaoka, M.I. O’Connor, N.E. O’Connor, R.J. Orth, F. Rossi, J. Ruesink, E.E. Sotka, J. Thormar, F. Tomas, R.K.F. Unsworth, M.A. Whalen, and J.E. Duffy. 2018. Latitude, temperature, and habitat complexity predict predation pressure in eelgrass beds across the Northern Hemisphere. Ecology 99: 29-35.

Ries, L., R.J. Fletcher Jr., J. Battin, and T.D. Sisk. 2004. Ecological responses to habitat edges: mechanisms, models, and variability explained. Annual Review of Ecology, Evolution, and Systematics 35: 491-522.

Ruesink J.L., C. Gross, C. Pruitt, A.C. Trimble, and C. Donoghue. 2019. Habitat structure influences the seasonality of nekton in seagrass. Marine Biology 166:75, DOI: 10.1007/s00227-019-3519-z

Ruffell, J., and R.K. Didham. 2016. Towards a better mechanistic understanding of edge effects. Landscape Ecology 31: 2205-2213.

Ruffell, J., R.K. Didham, P. Barrett, N. Gorman, R. Pike, A. Hickey-Elliott, K. Sievwright, and D.P. Armstrong. 2014. Discriminating the drivers of edge effects on nest predation: forest edges reduce capture rates of ship rats (Rattus rattus), a globally invasive nest predator, by altering vegetation structure. PLoS ONE 9: e112098.doi: 10.1371/journal.pone.0113098

Selgrath, J., K.A. Hovel, and R. Wahle. 2007. Effects of habitat edges on American lobster abundance and survival. Journal of Experimental Marine Biology \& Ecology 353:253-264.

This article is protected by copyright. All rights reserved 
Smith, T.M., J.S. Hindell, G.P. Jenkins, R.M. Connolly, and M.J. Keough. 2011. Edge effects in patchy seagrass landscapes: the role of predation in determining fish distribution. Journal of Experimental Marine Biology and Ecology 399: 8 - 16.

Stavely, T.A., D. Perry, R. Lindborg, and M. Gullström. 2017. Seascape structure and complexity influence temperate seagrass fish assemblage composition. Ecography 40: 936 - 946.

Tanner, J.E. 2005. Edge effects on fauna in fragmented seagrass meadows. Austral Ecology 30: 210218.

Villaseñor, N.R., W. Blanchard, D.A. Driscoll, P. Gibbons, and D.B. Lindenmayer. 2015. Strong influence of local habitat structure on mammals reveals mismatch with edge effects models. Landscape Ecology 30: 229-245.

Whalen, M.A., J.E. Duffy, and J.B. Grace. 2013. Temporal shifts in top-down vs. bottom-up control of epiphytic algae in a seagrass ecosystem. Ecology 94: 510-520.

Yarnall, A.H. and F.J. Fodrie. 2020. Predation patterns across states of landscape fragmentation can shift with seasonal transitions. Oecologia 193: 403-413.

Yeager, L.A., C.L. Acevedo, and C.A. Layman. 2012. Effects of seascape context on condition, abundance, and secondary production of a coral reef fish, Haemulon plumierii. Marine Ecology Progress Series 462: $231-240$.

Yeager, L.A., D.A. Keller, T.R. Burns, A.S. Pool, and F.J. Fodrie. 2016. Threshold effects of habitat fragmentation on fish diversity at landscape scales. Ecology 97: 2157-2166.

This article is protected by copyright. All rights reserved 


\section{Tables}

Table 1. Predictors included in each of the ten candidate models for predation risk evaluated at each

\section{Model Predictors}

Edge proximity * habitat degradation + shoot density + epibiont biomass + crustacean biomass

2 Edge proximity * habitat degradation + shoot density + crustacean biomass

3 Edge proximity * habitat degradation + shoot density

$4 \quad$ Edge proximity * habitat degradation + crustacean biomass

5 Edge proximity * habitat degradation + epibiont biomass

6 Edge proximity * habitat degradation

7 Edge proximity + habitat degradation

$8 \quad$ Edge proximity

9 Habitat degradation

$10 \quad$ Null model

site. Shoot density, epibiont biomass, and crustacean biomass all were $\log _{10}$ transformed for analysis. 


\section{List of figures}

Fig. 1. Locations of the 17 sites used in the study.

Fig. 2. Effect of location in the patch (edge vs. interior) and habitat degradation $(50 \%$ and $80 \%$ habitat removal) on predation risk at each site. Sites are arranged from north (top) to south (bottom). Site codes as in Appendix S1: Table S1. Odds ratios (+95\% confidence intervals) represent (a) the odds of being consumed by predators at the patch edge compared to the patch interior; (b) the odds of being consumed by predators in 50\% habitat removal plots compared to ambient plots; and (c) the odds of being consumed by predators in $80 \%$ habitat removal plots compared to ambient plots. Overall odds ratio for all sites combined is shown at bottom beneath horizontal dotted line. Blue symbols $=$ Atlantic sites; green symbols $=$ Pacific sites .

Fig. 3. Effects of (a) habitat degradation treatment, and edge-vs.-interior effect sizes ("edge effect size") for (b) shoot density, (c) epibiont biomass, and (d) crustacean biomass on the strength of edge effects on predation risk. The strength of edge effects on predation risk is represented by the log of the edge-vs.-interior odds ratio in all panels, with positive numbers representing greater odds of being consumed by predators along patch edges compared to patch interiors. For effect sizes, values $>0$ indicate higher density or biomass along the patch edge compared to the patch interior. For clarity, results from only ambient plots are shown for crustacean biomass. Boxplots show median (solid line), $25 \%$ and $75 \%$ quartiles (rectangle), and $90 \%$ of the range (whiskers). Site codes as in Appendix S1:

Table S1. For all panels, blue $=0 \%$ habitat loss, yellow $=50 \%$ habitat loss, and green $=80 \%$ habitat loss. 


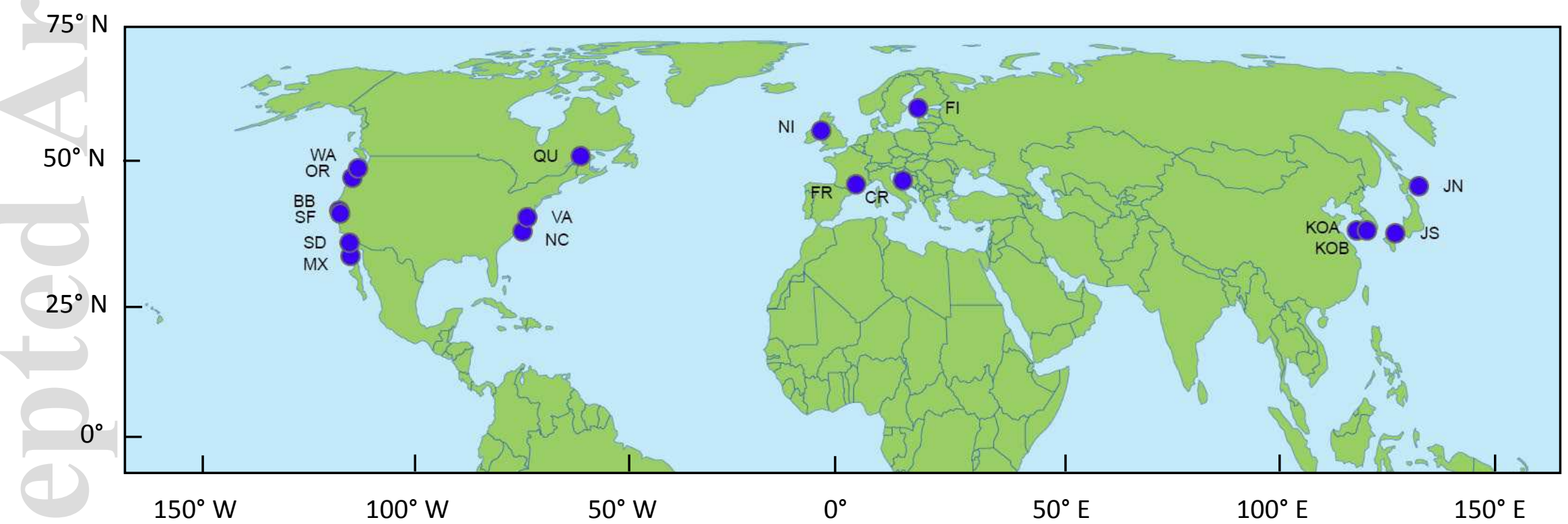

This article is protected by copyright. All rights reserved 
a. Edge vs. interior

Risk higher in patch I Risk higher along interiors patch edges

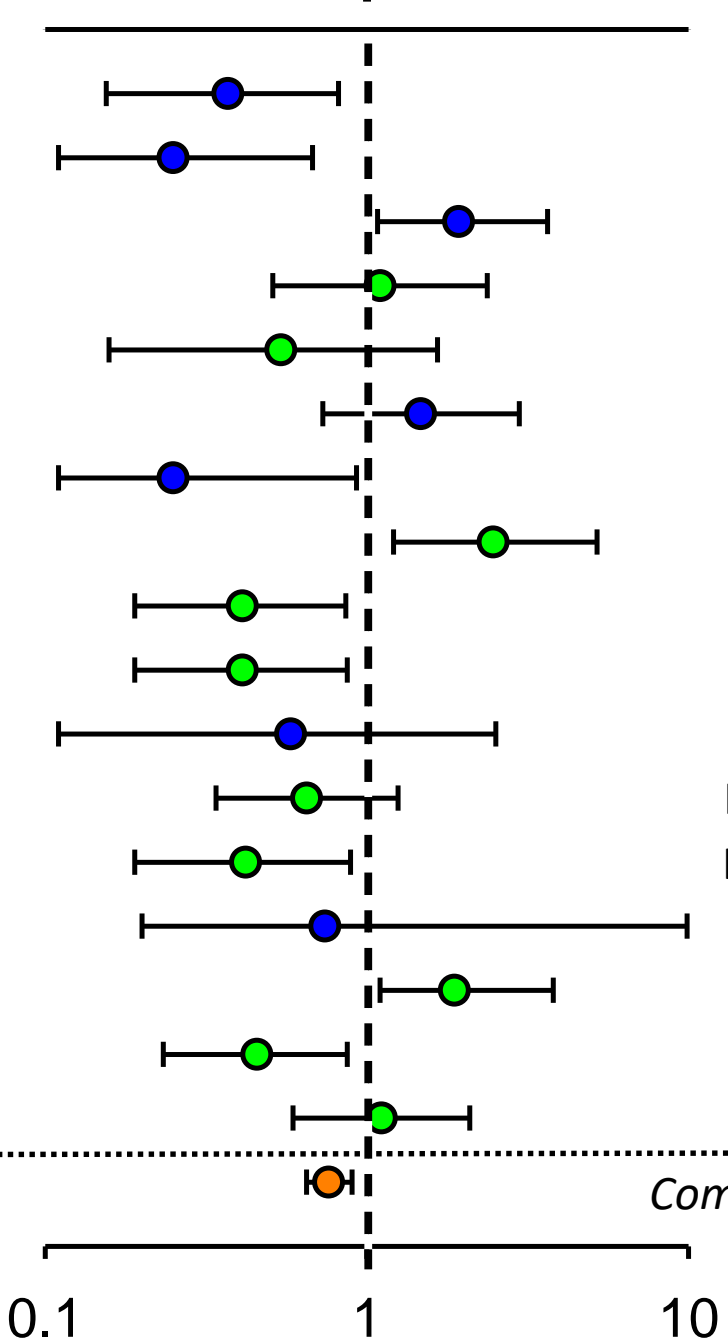

100.

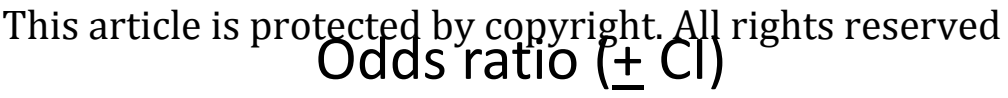

\section{b. $50 \%$ habitat removal}

Risk decreases with I Risk increases with degradation I degradation

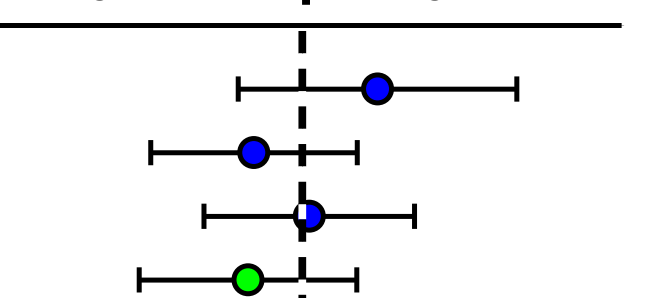

OR

CR

FR

JN

$\mathrm{BB}$

SF

VA

KOA

KOB

NC

SD

MX

mbined

0.1
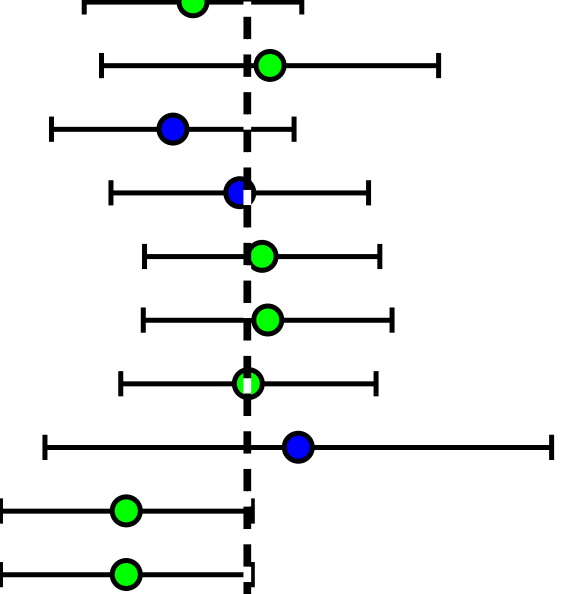

1

INA NC

10
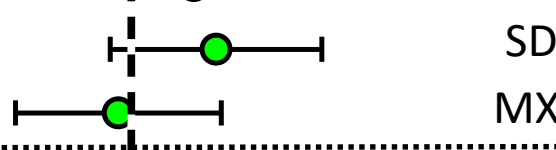

$\mathrm{Oa}$

1

1

Odds ratio $( \pm \mathrm{Cl})$ c. $80 \%$ habitat removal

Risk decreases with I Risk increases with degradation I degradation

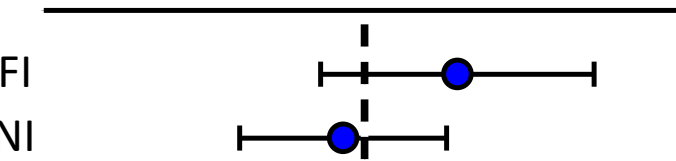

QU

WA

OR

CR

FR

$\mathrm{BB}$

SF

VA

KOA

KOB

JS

$\mathrm{MX}$

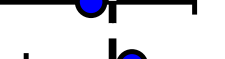

1
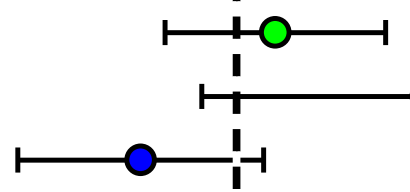

1

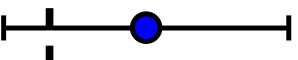

$\longrightarrow$
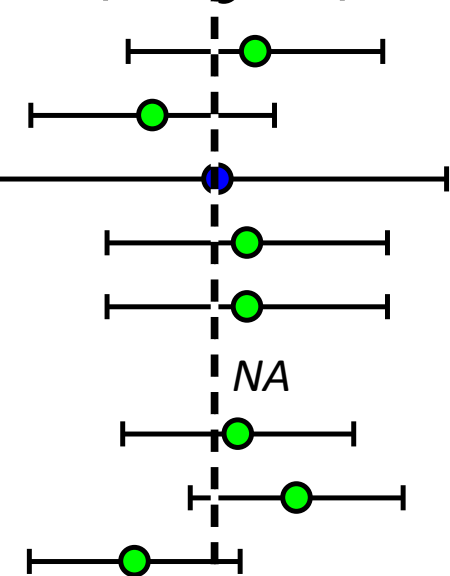

Combined

$10 \quad 0.1$

1

Odds ratio $( \pm \mathrm{Cl})$ 

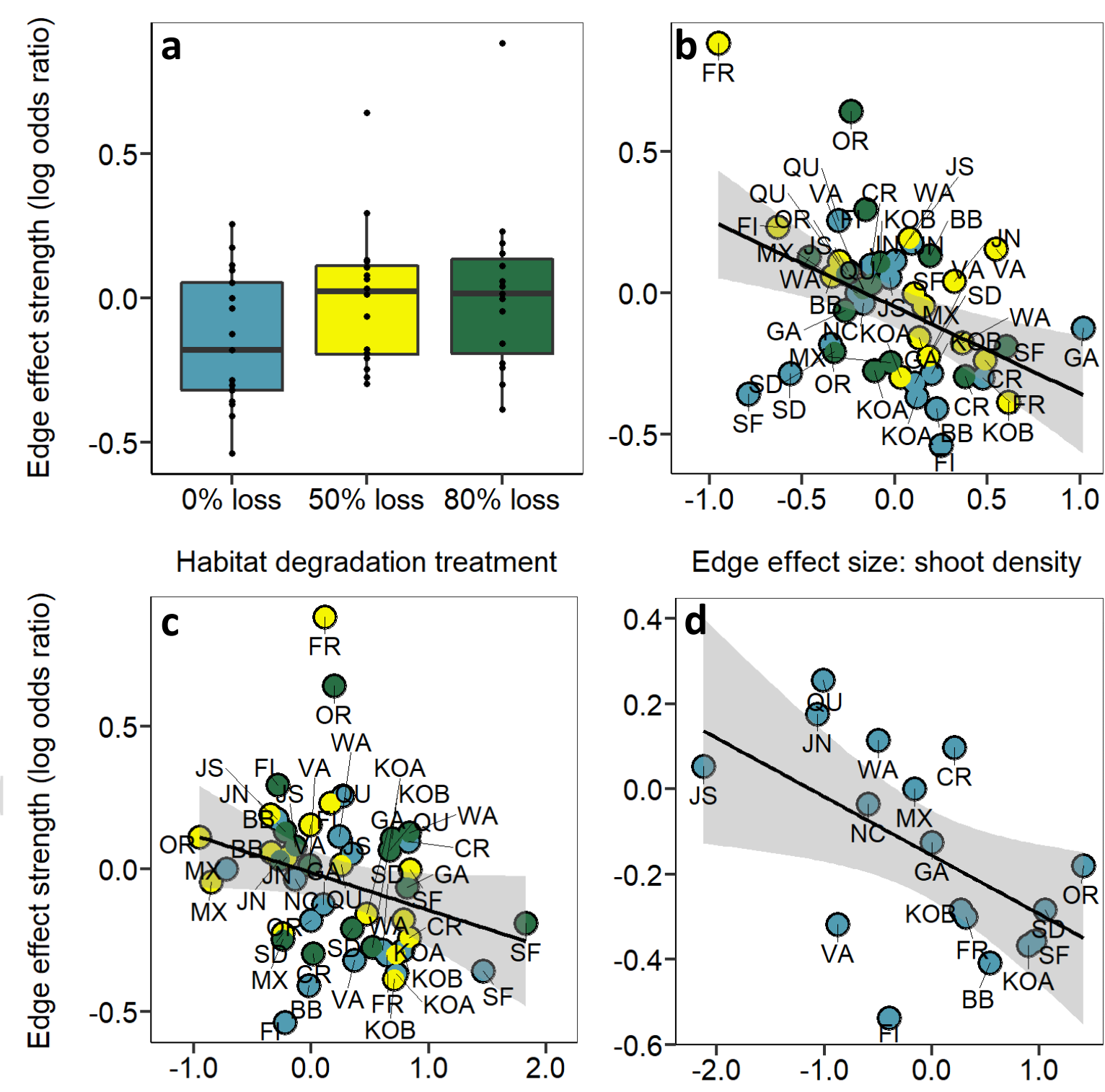

Edge effect size: shoot density

Edge effect size: epibiont biomass

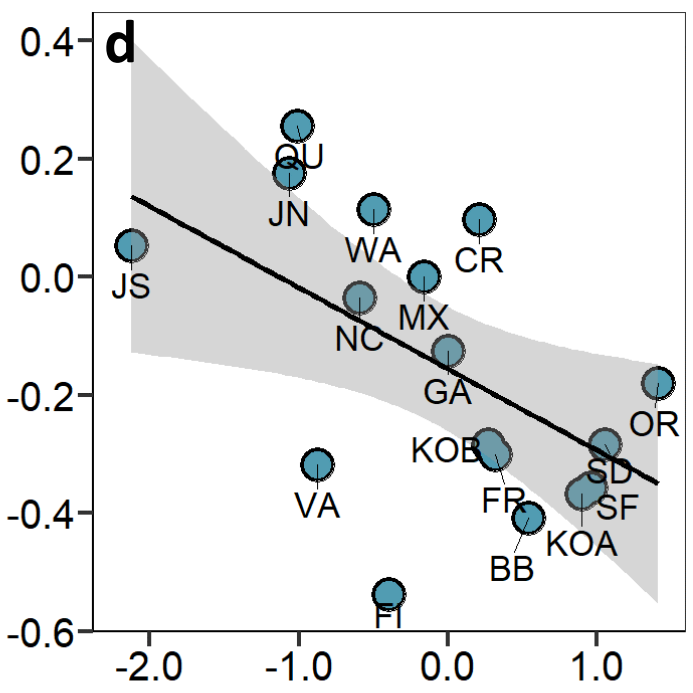

This article is protected by copyright. All rights reserved 